\title{
Tailoring Educational Elements for Academic Teaching - The JurMOO
}

\author{
B. Nett, B. Huber, S. Knirsch, L. Meyer, B. Remmele, \\ F. Röhr, B. Schinzel, and B. Stingl \\ IIG - Modell, University of Freiburg, Germany
}

\begin{tabular}{|c|c|}
\hline $\begin{array}{l}\text { nett@modell.iig.uni-freiburg.d } \\
\text { knirsch@modell.ilg.uni-treiburg.de }\end{array}$ & $\begin{array}{l}\text { e Ninjana66@hotmail.com } \\
\text { lea@modell.IIg.uni-frelburg.de }\end{array}$ \\
\hline imeleamodelifia uni-treibura de & roehr@modell.ilig.uni-freiburg.de \\
\hline schinzel@modell.Ilg.unl-trelburg.de & stingl@modell.IIg.unl-trelburg.de \\
\hline
\end{tabular}

\section{Abstract}

The RION project (financed by BMBF) aims at improving Computer \& Law (C\&L) teaching in Germany while implementing Web-based media. For the fluid and interdisciplinary field of C\&L, educational material is very scarce. Furthermore, educational cultures differ according to the divers affiliations of C\&L. Therefore, the RION platform will present a variety of documents online, which have not been accessible on the Web before.

However, publishing law collections online can only be one step to improve C\&L teaching. Therefore, RION is trying to develop a didactical conception for the new platform, the main focus being on cooperative, practice-oriented learning and gender mainstreaming. Due to the diversity and the constraints given in the project, the RION team does not look for the "ideal platform", but instead tries to tailor promising elements of possible C\&L online learning. In this text, the example of JurMOO, which we tested in C\&L teaching, is used to demonstrate this.

Keywords: Tailoring, Education, MOO, Computer \& Law, gender mainstreaming, constructivism, practice, CSCL

\section{Introduction}

Computer \& Law institutes, in Germany, belong to laws, computer science, and economic faculties. Its issues are new and shifting rapidly, at the same time comprising of complex implications. Studying Computer \& Law, therefore, remains a challenge. As is assured by our own evaluation, Computer \& Law has a comparatively low percentage of female students.

According to Kilian (2001), Computer \& Law is an interface between teaching and research. Furthermore it combines the investigation into computer-mediated cooperation of people working in laws with proposals regulating their organizational framework. Furthermore, Computer \& Law has to analyze and participate in related jurisdiction.

Material published as part of these proceedings, either on-line or in print, is copyrighted by Informing Science. Permission to make digital or paper copy of part or all of these works for personal or classroom use is granted without fee provided that the copies are not made or distributed for profit or commercial advantage AND that copies 1) bear this notice in full and 2) give the full citation on the first page. It is permissible to abstract these works so long as credit is given. To copy in all other cases or to republish or to post on a server or to redistribute to lists requires specific permission from the publisher at Publister@intormingscience.org
The German Ministry for Education and Research, $\mathrm{BMBF}$, finances the RION project aiming at the improvement of Computer \& Law teaching when implementing new media. RION is dedicated to promote cooperative forms of learning, to orient education more on practice, and to make Computer \& Law more attractive to female students. 
In this context, the RION project investigates into the advantages of tailoring a MOO (JurMOO) according to the demands in Computer \& Law teaching. One special tailoring will be explained in this paper: after a short general overview over computer-based learning and an outline of Computer \& Law teaching and MOOs, our conception of using JurMOO for virtually supporting academic face-to-face seminars will be explained.

The organizational scheme of RION is given in the following graphic:

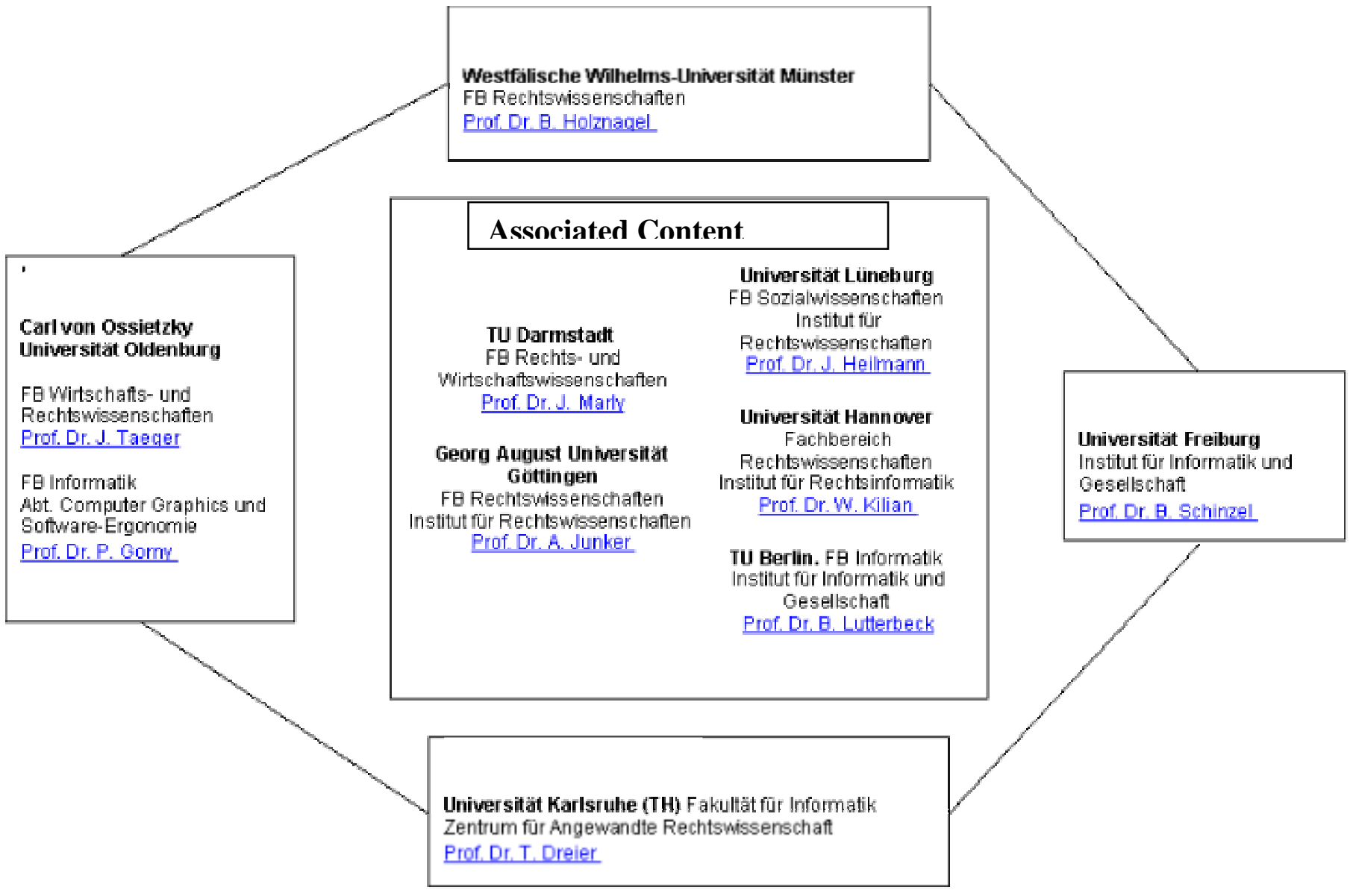

Major aims of the RION project are to care about competence instead of limiting the efforts to the field of cognition, to foster exchange between academic teaching and practice, and to promote gender mainstreaming.

In the gender discussion, adopting a constructivist stand means to deal with the question how gender is used in practice to assure or limit the chances of students. In certain settings, for example, basing communication on computer use could be a blockade for women to participate if they have worse access to computers (Campbell, 1999). However, our first findings in our field suggest that there seems to be little difference in access to computers and Internet.

Nevertheless, educational platforms have to avoid any gender bias in the navigation and in the representation of knowledge. But as gender is seen as a social construction by constructivists, avoiding related bias, furthermore, requires empirical experience with the notion of gender in the given field. This also implies, for example, the question why Computer \& Law seems - to a certain degree - to be more unattractive for female students than for male ones. 


\section{Computer-based Learning}

Working on educational platforms, it should be good to know something of the history of related efforts. Even before any systematic use of computers, there had been a discussion on "learning machines". Skinner (1971) interpreted teaching along the lines of behaviorist ideas as a form of conditioning students. From this point of view, teaching was very similar to pouring cognitive content into the heads of the students. In this context, the behavior of the students was studied in order to be able to adapt to it, for example, by proceeding faster or slower (Greif et al, 1989). "Pacing" is one method of adapting the speed of teaching to the success of the learner, which is automatically evaluated by means of ongoing tests. In order to achieve this, the steps between the educational elements, the number of explanations, or the time in between two lessons can be changed.

Computer Assisted Instruction (CAI) tried to develop drill programs, tutorials, simulations and explanatory tasks (Steinberg et al., 1977-88). The use of the computer should help to structure teaching by making use of experiences in learning contexts. The easiest and first idea was to implement "pacing" into the student-computer interaction.

But such linear programming of teaching did not fulfill all demands on adaptivity. Teachers, by their implicit knowledge of the students, sometime adapt teaching according to specific teaching strategies. Stulorow (1965), therefore, had proposed a more sophisticated programming of teaching machines involving experiences with learners, their interests and suchlike as the basis for educational strategies.

In computer science, related ideas were adopted. Intelligent tutorial systems (ITS) were developed to use intelligent agents (IA) to structure the navigation in expert components on one hand and the representation (Strittmatter et al., 1997) of retrieved knowledge on the other dynamically according to specific learner components. Adaptive user interfaces (AUI) were other tools supporting users by means of adaptive hypermedia (AH) or intelligent multimedia (IMM) (Specht, 1998).

Moreover, it must not necessarily be the computer which adapts itself in a given way, but the adaptation of teaching itself could be made adaptable. Teachers and learners were discovered as users who should be able to influence the teaching system, which thus was not only adaptive, but adaptable.

However, computer-based learning remained under critic. Proponents of computer use in teaching admired the computer for its capacity and speed to deliver data to any point of the world. Pessimists, however, saw computer-based teaching destroying any systematic form of education in favor of unstructured "learning on demand" (Kerres, 2000, pp.170-172).

Formalizing teaching in order to adapt it to anticipated different learner behaviors is very timeconsuming. Therefore, in reality, the adaptation of teaching systems has often been more based on the intuition of the programmer than on empirically tested findings (Leutner, 1992). Furthermore, more information can produce less competence to solve concrete problems (Johnson-Laird et al., 1989). Education, therefore, should promote practice-related competence among the students, which is more than supporting cognitive content.

In practice, experience always is situated (Suchman, 1987). This implies, that among experts a lot of knowledge always remains tacit (Nonaka, 1997). Information has to be framed to be meaningful in a given context (Schön, 1983), which can be a basis for misunderstanding - or for reflexion (Wenger, 1998). Context is important while collecting, storing and retrieving data.

Constructivism focuses on contextuality as the interface between the individual construction of the self and the social environment. First constructivists did not deal much with computer use in education, contextuallity was only seen as a problem for computer use in programmed teaching (Duffy et al., 1992). A different view became possible, when contextualization was discovered as a chance for education: In the 90s, constructivism became popular in pedagogics (Arnold, 1997). 
The interactive potential of the computer moved into the center of interest, while it had been more in the periphery at the beginning (Specht, 1998). Students should no longer be considered as mere consumers (De Paula, 1999). Instead, their involvement should be promoted by making it decisive in regard of what happens (Schmidt, 1994, Müller, 1996; Siebert, 1999). Programmed learning became a frame for integrating contextuality. In ELM, for example, episodic experiences such as examples of poor task-fulfillment are used for structuring teaching strategies (Specht, 1998).

As another stream of development, computer supported collaborative learning emerged besides programmed learning as a new field trying to orient education more to practice. This means two different things which both were fostered with the boom of constructivism: The student should learn by practice about practice (Spiro, 1992). On the one hand, the student had to become competent to deal with practice. In order to achieve this, teaching platforms (Niegemann et al., 1999), for example, could be oriented more on cases (Kerres, 1998). On the other hand, learning is a situated and reflexive activity of its own (Greeno et al., 1993). Here, practice orientation means that educational tools should support the cooperation of the students.

Schulmeister (1997) points out the necessity of docking teaching elements to the self-construction of the students - involving the existing interaction with its roles in students and teachers groups. The teacher's role thus becomes part of the story: it can no longer merely be based upon a cognitive lead, but has to be legitimized and reflected according to the aims of education on the one hand, on the competence of managing the learning process effectively on the other (Busse, 1999).

Goldstein (1989) argues that media should be chosen on behalf of didactical ideas. In this context, MOOs are bad means for simply distributing traditional top-down teaching (Bruckman et al., 1995), but instead are able to support active groups of learners (Rogoff et al., 1998). For us, therefore, the potential of the MOO is its combination of information and communication, and for easy shifts between them (Hoadley, 1999).

MOOs can be seen as sets of websites, which are textually described as "rooms", "characters", and other "objects". One can "walk" into rooms, read the related descriptions, "talk" to the people in the room, and search for people, rooms and objects. The geographic metaphor is used to structure and motivate interaction, which (like in a chat) is communication, i.e.: exchange of written utterances.

The acronym MOO consists of another acronym, which is MUD. A MUD is a multi-user domein, in an elder terminology: a multi-user dungeon (The genesis of MOOs was related to computer games). A MOO is a Mud object oriented. This means that the whole setting including the "characters" is programmed in an object-oriented manner - and thus all elements may be changed (Haynes et al., 1998, p.2).

This includes the possibility for participants to influence the representation of their own. Amy Bruckman, therefore, calls them "identity workshops" (Haynes et al., 1998). MOOs could be seen as Ericson`s "psychosocial moratioria": opportunities to try out identities. Such opportunities normally being very scarce in ones life cycle, they were important tests of "quality standards" of ones own life without too much of a risk.

By describing a "character" as a representation of oneself, the Mudder (a real world person participating in a MUD) can experiment with social roles. By writing, the students interact with other "characters" representing other students, tutors, or others. Interacting thus means "talking" to each other by means of writing. Besides "talking", there is "emoting": describing actions of the own character - again by writing. Furthermore, there are commands a student may use (if he is entitled to programming). The world of the MOO is mostly text-based like a chat, but, in contrast to a chat, is "a living, ever-changing ... environment" (Holmevik et al., 2000, p.xv) which can be altered by the users themselves. Therefore, MOOs have become very popular in the US, especially for foreign language teaching. 
During the stay in a MOO, users are represented by their avatars. In the "rooms", they may "meet" the avatars of other users, of those of the programmers and some evaluator, and even "NPCs" (non playing characters"), softbots (see: Broll, 1998, p.15-17) used for animation or questioning. Users can "fetch" (read) and "drop" (upload) own materials, and describe their own characters.

\section{Tailoring JurMOO according to Computer \& Law Teaching Demands}

For Bourgeoin (1999), besides expansiveness, tailorability is of mayor importance for learning platforms which should support cooperative learning. MOOs, in this context, seem promising tools. The geographical metaphor makes it possible to implement "rooms" according to the learning context given, and to continuously further adapt it with the participation of the users. As a Web-based open-source tool, links can be annotated at any "place" to other Web-based information sources or suchlike. However, tailoring a MOO requires understanding of the requirements in the given field. Only on this basis, it is possible to discuss promising features and to implement them in the MOO.

The RION team followed Schulmeister (1997) and started from existing interaction structures. We investigated into Computer \& Law teaching among the given partners. Our idea, in this context, was to start analyzing the existing forms of education, to contrast them with our aims of promoting cooperation, practice-orientation and gender mainstreaming, and to anticipate possible alternatives to existing educational procedures and forms. This field was very diverse.

Especially laws education was unique and differed much to other disciplines. In laws, students cannot choose between focuses of interest for the final examination at all. Instead, all students learn the same canon of laws. This leads to the situation that the vast majority of students joins private "repititors". Practice and specialization, in laws, only begins after studying during the years of the "referendariat". Former students told us that they felt completely unprepared, when they had been "thrown into practice", and that they learned more in their "referendariat" than in the whole of their studies at the university. In such environments, the possibility for self-organized cooperative learning can be very limited, and projects dedicated to C\&L (although of fast growing importance, still a peripherical field in laws) cannot produce wonders.

Discussing this with the staff of our partners, tutors of one partner laws institute complained about the seminar culture in laws education in general. They described a bad-case scenario as follows: In general, vacancies in seminars are scarce is this mass faculty. Therefore, students join preliminary seminar meetings in order to find some. If they are lucky, they get a subject, which they have to study, describe, and, afterwards on the seminar, present. Due to the given constraints, this subject has not always much to do with the specific interest of the student - students are happy if they have any at all.

The preliminary seminar meeting is organized some month before the seminar in order to allow students to prepare their papers. Students only seldom use the opportunity to discuss their papers before the seminar event, which leads to misunderstandings, students sometimes giving wrong emphases to their papers.

The presentation of the paper is on the seminar, often a two-day event. The professor, in order to appear interested and polite, normally asks one or two questions after a presentation. The auditorium, however, is more or less passive, which - to a certain degree - is due to the poor understanding of what the others present. So, students only "wake up" when it is up to her / him to read her / his paper. Discussions among the students are more than rare.

The RION team analyzed this setting. Of mayor importance, in this context, seems an integration of the students into the preparation of the seminar, an awareness of what the other students are doing, and cooperation. For the promotion of cooperation, the coordination of the contributions of the students remains a 
promising field. In the situation given, coordination between different presentations for the seminar is only organized, if - and in so far as - students contact the docent or tutors before a seminar, which occurs seldom. Giving the students the possibility to discuss their work together provides them the opportunity to take over from other presentators, or vice versa. Obviously, this is related with interests, and discussing conflicting ones thus can be a promising means to promote a cooperative working culture. Furthermore, it may produce more awareness of the implications of the individual work among the students.

The RION team developed a concept for a virtually supported seminar preparation by MOO. The distributed RION team defined its attempt as a virtual supported preparation of a face-to-face seminar, dedicated to provide students with access to context information while preparing their papers. The main goal, in this context, was the establishment of a structured and effective communication between the students among each other and with the tutors. With such communication yet being marginal, the new media should contribute to a better coordination of seminar presentations. Students becoming aware of the inter-relations of their papers were also expected to be more interested in the papers of the other students. Furthermore, competence in virtual teamwork and in media use could be effects of the attempt.

In order to achieve these goals, the project should include a new preparation procedure and an online onthe-job training. To avoid frustration, there should be a frame for the cooperation, organized by tutors and based on jour fixes for remote tutoring. This means that while students may meet in JurMOO at any time they want, there are certain virtual meetings in JurMOO with the tutors on fixed times ("jour fixes").

For our evaluation, we saw a lot of interesting topics such as navigation, interaction, and the use of emoting, all interaction being stored. Analysis should, for example find out, if there is a promotion of collaborative versa individualistic behavior in JurMOO, and how gender affects the JurMOO usages. The most basic question, however, remained if laws students, mostly accustomed to graphical user interfaces (GUIs) such as used, for example, in Microsoft Office, would accept a merely text-based, "stone-age" (in terms of the interface) environment, and if they would really use it.

Personal data should be collected with a special participation list to be distributed on the preliminary seminar meeting including email address, gender, computer literacy, Internet access, and chosen JurMOO name. We decided to have a specific authentification for seminar members to be implemented centrally by our programmer. The extended seminar list should be a basis for this procedure. Students should be able to read general information and news, upload outlines and summaries of the other students, and to annotate documents of others. The tutors and the evaluator should be able to evaluate online.

The project start should be the publishing of the seminar conception, the preliminary seminar meeting being the first face-to-face element. After the distribution of the seminar tasks, the RION team gives only a short demonstration of JurMOO on this meeting. This preliminary seminar meeting is followed by a distributed online JurMOO training consisting of 2 evenings. From that time on the students "meet" in the JurMOO every fortnight at a given time, tutors being virtually present. On a given date, students are asked to upload the outlines of their papers and to comment on those of the other students. The same should be done later with a summary. These individual uses of asynchonous activities are reflected on the common synchronous discussions, which are attended by the tutors.

We organized a pre-test using students and collegues not accustomed to MOOs in order to see, if they could learn and interact only with the "help" tools developed by us. The pre-test showed that participants had little problems to use JurMOO. However, it took nearly one fifth of the training time to bring the test persons in one "room" by means of JurMOO specific communication only. Therefore, the RION team decided to start the seminar preparation with the training in one room on a "jour fixe", and to start the training with the explication of communication. This makes it easier to explain the geographic metaphor and the related navigation according the lines of its potential to structure interaction. This proved to be a very simple, but also very powerful means of structuring the training. 
The help features developed by the RION team obviously were very effective. We had described all anticipated forms of student-computer and student-student interaction on index cards. Index cards are well known in laws learning environments. The index cards were paper prints, which could be placed on the desktop beside the computer. Obviously these were so powerful tools that no student had to use the "emergency" (to call the tutor by telephone).

However, some students got lost for a while during certain activities. One student commented "One moment without concentration and one is off the train". However, students continued training individually, playing along with JurMOO features in non-tutored times. Thus on the first meeting after the training, students had forgotten one command or another, but in general, they were able to cooperate by means of JurMOO.

Another finding of our pre-test was that training many students at the same time is not advisable. Tutoring, in this respect, is a different thing. Therefore, we decided to divide the seminar group in four parts of around 6 participants, assembling them in three related group rooms. Using 3 tutors seems to be a inefficient arrangement. However, training can go along the lines of the index cards and does not require preparation. Thus the training for some twenty students took only $6 \mathrm{~h}$, and it would be no problem to have it done with only one single tutor, if he organizes different times for the different training sub-groups. However, regarding the whole setting, two tutors seem to be best, for one can moderate the group, while another may coach a single student in another "room" at the same time, if (s)he seems to need individual help. This procedure tended to be very good in MOO practice.

One special problem in the pre-test was to communicate with persons that do not look onto the communication screen (the left / middle part of the screen) at all. In order to attract awareness for the communication channel of JurMOO in case of not-responding students, the programmer found a tool to scroll the entire communication frame very quickly. In the training, however, this was no more necessary due to the better structuration ("communication before navigation", and "starting in one room at one time"). Furthermore, an "emergency" channel existed based on the telephone numbers being exchanged among students and tutors. These simple measures proved to be very powerful: in two online training sessions of 1 hour, participants learned the basic features of JurMOO in so far that they were able to use the basic features and to proceed by themselves.

Our target persons were adult students of Computer \& Law who should know about legal and moral rules. Although an explanation of "netiquette" normally should be integrated in any educational use of a MOO (Haynes et al., 1998, pp.5-8), we did not invest much time in that. The result was that, after a short period of unstructured chaotic interaction, some effective rules emerged "on the fly" - the tutors often being catalysts for related self-organization.

\section{Performance and First Findings}

The preliminary seminar meeting was attended by nearly precisely the same number of students as vacancies available, half of them being female students. The voluntary character of the seminar's Internet element was underlined by the docent who advised only "students with spare time" to participate before conducting the meeting as usual. In spite of obvious skepticism of the professor, advanced time $(9.15 \mathrm{pm})$, and the obvious necessity of additional efforts, students joined the virtually supported seminar preparation by JurMOO. Our demonstration of the JurMOO provoked great interest. All students had Internet access. One student even had tried out to support a previous seminar with an Internet Forum, an attempt, which failed due to lacking commitment. We collected the necessary information from the students, distributed some questionnaires and demonstrated JurMOO.

The online training some days later was so much enjoyed by the participants that even after the training, some students remained in JurMOO joking, discussing and making appointments. At the start of the test, 
the RION team itself had been skeptical if laws students would accept merely text-based media, but students used it with enthusiasm. There even have been some unexpected usages of the JurMOO. One male student uploaded different versions of his outline to document the progress of his work. The male student experienced in Forum-programming implemented a "back"-button in his room. A female student asked for an awareness-generating feature related to incoming JurMOO mail. This shows the creativity of the cooperating laws students while reflecting their media basis.

While all students used JurMOO to present the outline of their papers, annotations have mostly been made only in two ways: tutors commented on the proposals of the students and students commented on their own ("only a first attempt"). This means that students seldom used the opportunity to annotate the documents of other students. One possible interpretation could be to see it as a general tendency of students to be too nice to each other (see Veerman, 1999). However, this interpretation has no empirical grounding. Students uttered a lot of critique and proposals, but mostly by means of synchronous interaction, thus immediately being able to see the reaction and to react again. Instead, asynchronous annotations remain present as artifacts like a written offence left in somebody's document. This cannot so easily be reinterpreted like in a synchronous interaction ("sorry, it was only a joke"...). The lower hurdle and better framing of critique in synchronous tools seems to us to be a strong argument against Veerman's (1999) general preference for asynchronous ones.

Although our strategy to leave netiquette to the students tended to be satisfying in most cases, synchronous spontaneity could not solve all problems. The relative complex structure of the rooms and their undefined purpose made their use as a means to structure communication difficult. Students tended to remain in the plenum even to discuss "private" or sub-group issues waiting for a break to bring them forward, the related delays and the changing subjects causing some frustration. Not always the possibility to join other "rooms" was used. Obviously students did not know if they were, for example, allowed to leave a common meeting.

Another point was software ergonomy. On the one hand, many students complained that JurMOO does not support the complete German alphabet due to its anglophone origin. Another problem is the annotation, which works only by generating new documents: comments or hints (marker functionality) in given documents indicated by different colors etc. and information about author and time (history functionality) is not yet implemented in JurMOO. Furthermore, in JurMOO, there are two different possibilities to generate a document, this is by describing a "room" or by "dropping" an object. Tutor, after the seminar, complained about the irritation caused by these different ways in which students uploaded their content. However, tutors think that for the purpose of a virtual supported seminar preparation problems can be solved satisfying enough using additional and more concrete index cards on room usage and document handling.

As to the abstracts, students have made little use of the opportunity to upload them. This probably had to do with these abstracts being the last to be produced after finishing the seminar presentation: Shortly before the face-to-face seminar, obviously there arouse some hectic and abstracts have not been finished early enough to be discussed before. This interpretation is based on comments of the students. Furthermore, some students obviously had problems with basic concepts of scientific work such as "paper", "summary", "presentation", and "abstract": some students, for example, uploaded their summaries under the heading: "abstracts". The log also shows that related questions were quite numerous: "What should a presentation look like?" "Should it be presented with Powerpoint?" "How many slides?" "How long is a paper?" "Is there a difference between a presentation and a paper?"...

Discussing such basic and formal questions must not necessarily have produced a better quality of the individual results. However, it contributed basic knowledge to the students and a greater transparency to the seminar, made students feel more secure, and led (as the professor assured us) to greater homogenity between the individual presentations. This shared aesthetics in return made the understanding easier and fos- 
tered a certain feeling of community. Even the professor, having been very skeptical, reported that the seminar (unlike others) obviously needed no "warming up" phase, constructive discussions being so intense that he had to stop the students again and again in order to keep in line with the agenda!

A female tutor, who had feared a further isolation of the individual students by means of computerization, admitted that the use of JurMOO in the virtually supported seminar preparation had led to the contrary effect: an increase of interaction and even face-to-face appointments, meetings and discussions between the students. The average value of the fun factor given by students working for the preparation of this laws seminar dedicated to this simple, new and unknown software tool on a scale ranging from no fun $(=0)$ to enormous fun $(=10)$ was 6.8 !

This is interesting, as the female students were even more content with the use of this tool (7.4) than the male ones (6.3) which makes the use of JurMOO a tool for virtual supported seminar preparation promising for gender mainstreaming, as well. Comparing the ratings of male and female students, both evaluated JurMOO's influence on the quality of the individual presentations on the face-to-face seminar (m: 4.4 / f: 4.25) and the overall help provided by the tool (m: 5.7 / f: 6.0) pretty equally. In contrast, a relatively strong positive deviation of the ratings of the female students (besides the fun factor, see above) existed for JurMOO's contribution to the understanding of co-students and their presentations (m: 4.1 / f: 4.7), while positive deviations of the male ratings are related to the coordination impact of JurMOO for the seminar (m: 5.7 / f: 4.6).

One possible interpretation here could be, that male students saw the seminar preparation by JurMOO use more as a measure to improve the overall teaching quality of the seminar, whereas female students saw it more as a direct individual help for them, reducing information lags (in regard of the specific knowledge on computer technology / terminology predominant in C\&L issues ?) Additional research should be done here, as there could also be explanations different from this tentative one. Furthermore, the high acceptance of the JurMOO usage was not only due to the tool itself: besides other factors, the students explicitly appreciated the excellent work of the tutors and the support of our programmer who implemented many gimmicks after related proposals of the students. This is to say that the playing features of JurMOO made it easier for the students to accept the new tool, although, on the fixed tutored dates, they generally used it for task-related questions and not for amusement only.

In this context, the tutors were very important. In particular, they initiated rules and motivated "pioneers". This is especially important, as chatting normally starts with a "tentative socializing" with little structures and little hierarchy. While this phase is important for any emergence of "netiquette", there seems to be a related over-stability hindering the participants to switch over new interaction forms such as dealing with task-related questions. For untutored groups without strong "pioneer" personalities effective switching from preliminary chit-chat to task-oriented discussion may be problematic and, on the longer run, lead to "empty postboxes" and a decrease of interest and commitment: with the tutors, however, this had be no problem.

The tutors reported to be very content with using JurMOO for a virtual supported preparation of their seminar. To a certain degree this has to do with the tutor-student relation becoming more structured and more convenient at the same time: participants can join from their homes, and tutors may stick to the weekly time schedule and feel better prepared than being asked on occasional meeting in corridors. The tutors reported that the regular investment of time was counterweighted by the opportunity to place the session into calmer time slots such as evenings $(7 \mathrm{pm}-8 \mathrm{pm})$ without having their students protesting.

Even after the seminar, when we collected additional information about the students' experiences with JurMOO by related questionnaires (the evaluation of data is still going on), students asked for the maintenance of their JurMOO logins, because they wanted to keep in touch with each other by means of JurMOO. This fact, among others, showed the feeling of community among the seminar members. The 
RION team advised the students not to rely on JurMOO alone, the lack of fixed tutored dates otherwise surely causing more and more lonesome JurMOO visits and decreasing interest.

The RION team, instead, made the proposal (which was accepted and put into practice) to elect some responsible network member, to whom the others students can report all changes of Email addresses and who can thus administer an up-to-date mailing list with the help of the project team. The project tries to store the related mailing list with all participants of the seminar interested in further communication. Thus any student may initiate a meeting in JurMOO by announcing this on the mailing list. Due to the very little information to be stored, such hosting of mailing lists, which are administrated by the students themselves, could be interesting for future alumni work of their institutes.

\section{Conclusion}

Cleesman et al. (1999), when propagating problem-based learning, point out the necessity of intelligent pedagogical conceptions being more important for successful media use in education than costly programs. The problem to be solved by a virtually supported seminar preparation, in this context, is the coordination of students preparing their contributions for a common seminar.

Whereas effective communication rules emerged quickly among students and tutors, obviously the underlying navigation metaphor of JurMOO is too complex to be quickly explored and self-structured. Therefore, a simpler differentiation of rooms (no training rooms, for example) and a tutorial proposal of room usages (for example, on the online training) could make things easier for the students.

The tutors can react by acting like (or promoting) a "pioneer": once task-related discussions have been started, these are to be continued with enthusiasm by the students themselves. Without much efforts from the tutors, astonishingly, the vast majority of utterances during the "jours fixes" were purely task-related!

Virtually supported seminar preparations, for example by JurMOO, imply a high demand on tutorial work. On the other hand, for the tutors the implementation of JurMOO into a seminar preparation obviously has been accompanied with a motivational push, which transferred efforts into challenges. However, using JurMOO as a virtual support for the preparation of a seminar should be seen as a means for improving the quality of teaching, not to reduce the costs: although an open source tool, the tailoring, administration and tutoring requires quite some time.

JurMOO has demonstrated that discussion and cooperation, including task-related ones, which normally occurs very seldom among laws students before a seminar, can be promoted with a very simple tool. Being enabled to read the outlines of other students, to compare them with ones own proposal, to discuss them and even to negotiate about possible divisions of the issues, seems to be a great benefit. Students have been enthusiastic about their opportunity to communicate with each other and with tutors in the seminar preparation.

\section{References}

Arnold, R., Siebert, H. (1997). Konstruktivistische Erwachsenenbildung, Schneider, Baltmannsweiler

Bourgoin, G., Derycke, A. (1999). Integrating the CSCL Activities into Virtual Foundations of a new infrastructure for distributed collective activities, Proceedings of the CSCL1999 Conference, Maastricht 1999

Broll, W. (1998) Ein objektorientiertes Interaktionsmodell zur Unterstützung verteilter virtueller Umgebungen, GMD Forschungszentrum Informatik, Sankt Augustin

Bruckman, A., Resnick, W. (1995). The MediaMOO Project. Constructivism and Professional Community, Convergence

Busse, J. (1999). Dozentenhandbuch. Tübinger Studientexte Informatik und Gesellschaft, Uni Tübingen 
Nett, Huber, Knirsch, Meyer, Remmele, Röhr, Schinzel, \& Stingl

Campbell, K. (2000) The promise of computer-based Learning. Designing for Inclusivity. IEEE. Technology and Society Magazine, 18/4 1999/2000

Cleesman, R., Heileson, S.B. (1999). Supporting Problem-based learning in Groups in a Net Environment, in: Hoadley, C., Roschelle, J. (eds.:) Proceedings of Computer Support for collaborative Learning, CSCL 1999 Conference, Dec.12-15, Stanford University, Palo Alto, California

De Paula, R., Fischer, G., Ostwald, J. (1999). Courses as Seeds: expectations and Realities, Proceedings of CSCL 99

Duffy, T.M., Jonassen, D.H. (eds.) (1992). Constructivism and the Technology of Instruction, Lawrence Erlbaum, Hillsdale

Goldstein, E.B. (1998). Sensation and Perception, Wadsworth, Belmont CA

Greeno, J.G., Smith, D.R., Moore, J.L. (1993). Transfer of situated learning, in: Detterman, D.K., Sternberg, R.J. (eds.): Transfer on Trial: Intelligence, Cognition and Instruction. Ablex Publishing, pp.99-167

Greif, S., Kurtz, H.-J. (1989). Ausbildung, Training und Qualifizierung, in: Greif, S., Holling, H., Nicholson, N. (Hrgb.): Arbeits- und Organisationspsychologie, München, pp.149-161

Haynes, C., Holmevik, J.R. (1998). Highwired. On the Design, Use, and Theory of Educational MOOs, UMP, Ann Arbor

Hoadley, C.M. (1998). Between Information and Communication, Middle Spaces in Computer Media for Learning, in: Hoadley, C., Roschelle, J. (eds.:) Proceedings of Computer Support for Collaborative Learning, CSCL 1999, Stanford Univ., Palo Alto, California

Holmevik, J.R, Haynes, C. (2000). MOOniversity. A student's guide to online learning environments. Allyn and Bacon, Boston, London, Torronto, Sydney, Tokyo, Singapore

Johnson-Laird, P.N. (1989). The Computer and the Mind. An Introduction to Cognitive Science. Fontana, London

Kerres, M. (1998). Multimediale und telemediale Lernumgebungen: Konzeption und Entwicklung. Oldenburger Verlag München

Kerres, M. (2000). Potenziale des Lernens im Internet: Fiktion oder Wirklichkeit, in: Hoffmann, Hilmar (Hg.): Deutsch global. Sprache. DuMont, Köln, pp.170-195

KILIAN, W. (2001). WARUM RECHTSINFORMATIK? COMPUTER UND RECHT 17/2, PP. 132-135, 2001

Leutner, D. (1992). Adaptive Lehrsysteme, Instruktionspsychologische Grundlagen und experimentelle Analysen, Beltz, Weinheim

Müller, K. (1996). Konstruktivismus: Lehren, Lernen, ästhetische Prozesse. Kriftel, Berlin, Luchterhand

Niegemann, H.M., Wedekind, J. (1999). Referenzmodelle für die Entwicklung von interaktiven Lernsystemen. HMD Praxis der Wirtschaftsinformatik 36, S.54-64

Nonaka, I., Takeuchi, H. (1997). Die Organisation des Wissens. Frankfurt am Main, Campus

Rogoff, B., Matsuov, E., White, C. (1998). Models of Teaching and Learning: Participation in a Community of Learners", in Olsen, D.R., Torrance, N. (eds.): The Handbook of education and Human Developments. New Models of Learning, Teaching and Schooling, Blackwell, Oxford, pp.338-414

Schmidt, S.J. (1994). Kognitive Autonomie und soziale Orientierung. Konstruktivistische Bemerkungen zum Zusammenhang von Kognition, Kommunikation, Medien und Kultur, Suhrkamp, Frankfurt am Main

Schön, D.A. (1983). The reflective Practitioneer: How professionals think in action, Basic Books, New York

Schulmeister, R. (1997). Grundlagen hypermedialer Lernsysteme: Theorie, Didaktik, Design, 2. Auflage, München, Wien

Siebert, H. (1999). Pädogogischer Konstruktivismus. Eine Bilanz der Konstruktivismusdiskussion für die Bildungspraxis. Luchterhand

Skinner, B.F. (1971). Ein Jahrzehnt Lehrmaschinen, in: Glaser, R. (ed.): Programmiertes Lernen und Unterrichtstechnologie, Cornelsen-Velhagen und Klasing, Berlin, pp.5-19

Specht, M. (1998). Adaptive Methoden in computerbasierten Lehr-/ Lernsystemen, GMD Research Series, 1998, No.24, GMD, St. Augustin

Spiro, R.J., Feltovich, P., Jacobson, M., Coulson, R. (1992). Cognitive Flexibility, Constructivism and Hypertext: Random Access Instruction for Advanced Knowledge Acquisition in ill-structured Domains, in: Duffy, T.M., Jonassen, D.H. (eds.): Constructivism and the technology of Instruction: a conversation. Lawrence Erlbaum, Hillsdale, pp.57-75 
Tailoring Educational Elements

Steinberg, E.R. (1998). Computer Assisted Instruction, A Synthesis of theory, practice and Technology, 1977-1988, Journal of Computer-based Instruction, 4, 117-121, quoted from Specht, p.54

Strittmatter, P., Mauel, D. (1997). Einzelmedium, Medienverbund, Multimedia, in: Issing, L. / Klimsa, P. (Hrg.): Information und Lernen mit Multimedia, 2. Auflage, Beltz Psychologie-Verlags-Union, Weinheim, Basel

Stulorow, L.M., Davis, D. (1971). Teaching machines and computer based systems, 1965, in: Glaser, R. (ed.): Programmiertes Lernen und Unterrichtstechnologie, Cornelsen-Velhagen und Klasing, Berlin, S.5-19

Suchman, L.A. (1987). Plans and situated actions, CUP, Cambridge, UK.

Veerman, A., Veldhuis-Diermanse, E. (1999). Collaborative Learning through computer-mediated communication in academic education, in: Proceedings of CSCL 1999, University of Maastricht

Wenger, E. (1998). Communities of Practice. Learning, Meaning and Identity, Cambridge University Press

\section{Biographies}

Dr. Bernhard Nett, Institut für Informatik und Gesellschaft, Modellbildung und soziale Folgen, AlbertLudwigs-Universität, Freiburg, Germany nett@modell.11g.un1-freıburg.de In combination with Sociology, Bernhard Nett studied International Cooperation and Philosophy (m.a. 1987) and Political Science and Economics (Ph.D. 1998) at the RWTH Aachen, where he lectured on Sociology. In industry, he worked as a consultant for Qualification for Participation at Mensch, Arbeit und Technik GmbH, Aachen (MA\&T), and as acting project coordinator for the OrgTech project at ProSEC, Informatik III, University of Bonn. Currently Bernhard Nett is a researcher of the RION project at the Institute for Computers and Society, Freiburg, and holds a post-doc position at Fraunhofer FIT-ICON (2001). His mayor research interests are participatory design, the integration of new media into existing contexts of learning, the threat on tacit knowledge in restructuration processes, civil society, exclusion, marginalization, and human \& civil rights.

Birgit Huber, Volkskundliches Seminar, Universität Bonn, Freiburg, Germany Ninjana66@hotma1l.com Birgit Huber studied European Ethnology, Sociology, (Contemporary) German Literature, and Economics at the universities of Passau and Freiburg (m.a. 2000). She had been a researcher of the RION project at the Institute of Computer and Society, Freiburg, before becoming researcher and teaching assistant at the Institute for European Ethnology at the University of Bonn. She is writing a dissertation on "work in virtual teams of the multi-media industry". Her mayor research interests are the didactics of online teaching, ethnography of virtual work, gender and IT, staging, experiences of body and gender in text-based virtual realities (MUDs and MOOs), the transformation processes in Eastern Europe (especially in Slovakia, Czech Republic and Romania) and European integration.

Susanne Knirsch, Institut für Informatik und Gesellschaft, Modellbildung und soziale Folgen, AlbertLudwigs-Universität, Freiburg, Germany kn1rsch@modell.11g.un1-tre1burg.de Susanne Knirsch studied Special-Needs Education at the University of Cologne. Having worked as a teacher for several years, she completed a vocational training in Desktop and Electronic Publishing and became screenplay writer and project manager for educational programs (computer-based training). In this context, she worked in Swiss and German publishing companies. As project manager at the Tele-Akademie der Fachhochschule Furtwangen for "New Educational Media: Multimedia and Tele-Teaching" she organized teaching projects for students and employed persons. Currently she uses her experience in tele-teaching and didactics at the Institute for Computer and Society, Freiburg, within the RION project.

Dr. Léa Meyer, Institut für Informatik und Gesellschaft, Modellbildung und soziale Folgen, AlbertLudwigs-Universität, Freiburg, Germany lea@modell.11g.un1-fre1burg.de Léa Meyer studied Mathematics and Physics at the University of Freiburg. She made her diploma in the f1eld of Mathematical Logics (Stability Theory) and took a position at the Institute for Computer Science and Social Research. There she worked in Theoretical Computer Science and lectured on different fields of Computer Science and Social Research. Her Ph.D. thesis was on probabilistic machine learning differentiating classes of learn- 
able languages. Due to her experiences and interest in tele-teaching, she played an important role for the RION project during its design and application at the BMBF.

Dr. Bernd Remmele, Institut für Informatik und Gesellschaft, Modellbildung und soziale Folgen, AlbertLudwigs-Universität, Freiburg, Germany remmele@modell.11g.un1-freiburg.de Bernd Remmele studied Sociology, History and Islamic Sciences at the University of Freiburg. He graduated 2001 with a Ph.D. thesis about the 'Genesis of the Machine Paradigm'. He lectured on Sociology and worked for the international Internet-based sociological teaching network LEC.

Currently he is coordinating the Germany-wide Internet-based juridical teaching network RION. His main areas of interest are sociology of cognition and culture as well as sociology of science and technology.

Frank Roehr, Institut für Informatik und Gesellschaft, Modellbildung und soziale Folgen, AlbertLudwigs-Universität, Freiburg, Germany roehr@modell.11g.un1-freiburg.de Frank Roehr studied mathematics (with a focus on computer science) at the RWTH Aachen. At ASCOM, Aachen, he served as system developer. Currently he is working as a researcher in the RION project at the Institute for Computer and Society, Freiburg. In this context, his main task is the administration of JurMOO. His major research interests are MUDs and MOOs and their evaluation. Further interests are representation theory, evolutionary algorithms and computers and society.

Prof. Dr. Britta Schinzel, Institut für Informatik und Gesellschaft, Modellbildung und soziale Folgen, Albert-Ludwigs-Universität, Freiburg, Germany schinzel@modell.i1g.uni-freiburg.de Britta Schinzel studied Mathematics and Physics at the universities of Vienna and Innsbruck and finished her Phil. Dr. thesis in the field of Algebraic Geometry. After working in the field of compiler-compilers in the German computer industry she returned to University and made her habilitation at the Technical University of Darmstadt in the field of Theoretical Computer Science. She became professor in Theoretical Computer Science at the RWTH Aachen, where she worked in different fields of Theoretical Computer Science, artificial intelligence, machine learning theory and in interdisciplinary projects together with sociology, linguistics, philosophy, medicine and biology. In the following she received a position as professor in Computer Science and Social Research at the University of Freiburg. Here she is working in different fields of technology assessment and computer applications in science and humanities. Especially she is emphasizing on distance learning in different subjects as well as in gender studies in computer science and at the border of information technology and science.

Benjamin Stingl M.A., Institut für Informatik und Gesellschaft, Modellbildung und soziale Folgen, Albert-Ludwigs-Universität, Freiburg, Germany stingl@modell.11g.un1-freiburg.de Benjamin Stingl studied German / English philology and psychology (m.a. 2000) at the universities of Hamburg and Freiburg. He worked in the project management of the LearnIT@ETH project for the ETH Zürich and was a consultant for information architecture at DesignConcepts GmbH, Furtwangen. Currently Benjamin Stingl is researcher of the RION project at the Institute for Information, Technology and Society, University of Freiburg. His research interests are cooperative learning, information architecture, usability design, the integration of new media into existing contexts or learning, the role of narrative and emotion in interactive fiction (believable agents systems). 